\title{
WEE1 inhibition by MK1775 as a single-agent therapy inhibits ovarian cancer viability
}

\author{
MINGHUI ZHANG ${ }^{1,2}$, DONYE DOMINGUEZ ${ }^{2}$, SIQI CHEN ${ }^{2}$, JIE FAN $^{2}$, LEI QIN $^{2}$, \\ ALAN LONG ${ }^{2}, \mathrm{XIA} \mathrm{LI}^{1}, \mathrm{YI} \mathrm{ZHANG}^{3}, \mathrm{HUIRONG} \mathrm{SHI}^{1 *}$ and $\mathrm{BIN} \mathrm{ZHANG}^{2,3^{*}}$ \\ ${ }^{1}$ Department of Obstetrics and Gynecology, The First Affiliated Hospital of Zhengzhou University, Zhengzhou, \\ Henan 450052, P.R. China; ${ }^{2}$ Robert H. Lurie Comprehensive Cancer Center, Department of Medicine, Division of \\ Hematology/Oncology, Northwestern University Feinberg School of Medicine, Chicago, IL 60611, USA; ${ }^{3}$ Biotherapy \\ Center, The First Affiliated Hospital of Zhengzhou University, Zhengzhou, Henan 450052, P.R. China
}

Received November 14, 2015; Accepted May 5, 2017

DOI: $10.3892 / \mathrm{ol} .2017 .6584$

\begin{abstract}
Wee1-like protein kinase (WEE1) physiologically serves a key function in maintaining the integrity of the cell genome through mediating the activation of cyclin-dependent kinase (CDK)1 and CDK2. Increased expression of WEE1 has been associated with the poor prognosis of patients with ovarian cancer. The present study aimed at examining the in vitro and in vivo antitumor activity of MK1775, a potent pharmacological inhibitor of WEE1, as a single agent against ovarian cancer cells. The cytotoxicity of MK1775 was examined in a panel of tumor cells using MTT in vitro. Subsequently, a cell apoptosis assay was performed in ovarian cancer SKOV3 and ID8 cells to characterize the function of MK1775 in tumor cell apoptosis, under either wild-type tumor protein 53 (p53) or null p53 status. In addition, cell cycle analysis and a western blot analysis were performed to validate the effect of MK1775 on cell cycle progression and to elucidate the underlying molecular mechanism of cell death. Finally, the in vivo antitumor efficacy of MK1775 as a single agent at a clinical well-tolerated dose was determined. A dose-dependent inhibitory effect of MK1775 on tumor cell viability was determined in distinct cell lines, including B16F10, LLC1, BPS1, EG7, ID8 and SKOV3. Results from the cell cycle analysis and western blotting indicated that MK1775 abrogated the $\mathrm{G}_{2} / \mathrm{M}$
\end{abstract}

Correspondence to: Dr Bin Zhang, Biotherapy Center, The First Affiliated Hospital of Zhengzhou University, 1 Jianshe Road, Erqi, Zhengzhou, Henan 450052, P.R. China

E-mail: bin.zhang@northwestern.edu

Dr Huirong Shi, Department of Obstetrics and Gynecology, The First Affiliated Hospital of Zhengzhou University, 1 Jianshe Road, Erqi, Zhengzhou, Henan 450052, P.R. China

E-mail: hrshi2011@163.com

*Contributed equally

Key words: MK1775, Weel-like protein kinase, ovarian cancer, ID8, SKOV3, monotherapy checkpoint through inhibiting the phosphorylation of CDK1 and inducing the apoptosis of ovarian cancer cells that lacked mutations in p53 and breast cancer 1 (BRCA1). Additionally, a significant antitumor effect of MK1775 was observed in C57BL/6 mice bearing syngeneic ID8 ovarian tumors. The results of the present study supported the use of MK1775 as a monotherapy agent in ovarian cancer. MK1775 was effective at inducing mitotic catastrophe, independent of p53 and BRCA1 mutations. Therefore, WEE1 inhibition by MK1775 requires additional investigation to identify novel combination approaches in ovarian cancer therapy with the current DNA damaging agents, including irradiation treatment and cell cycle checkpoint inhibitors.

\section{Introduction}

Ovarian cancer is the most common cause of cancer-associated mortalities in females diagnosed with gynecological malignancies, accounting for 22,000 new cancer cases (3.7\% of all cancer cases in females) and $\sim 140,000$ mortalities (4.2\% of all female mortalities) annually $(1,2)$. In spite of advancements occurring in cytoreductive surgery and chemotherapeutic techniques, the 5-year survival rate for ovarian cancer remains virtually unchanged due to the high metastatic and drug-resistant properties of the cancer. Thus, effective therapy is required.

Wee1-like protein kinase (WEE1), an important regulator for the cell cycle checkpoints, contributes to the upstream regulation of the cyclin-dependent kinase (CDK) complexes by mediating the activation of CDK1 (also known as CDC2) and CDK2 (3-5). CDK1/2 are well-known mediators of cell division, ensuring that the cell is healthy to undergo mitosis and subsequently driving the cell cycle through $\mathrm{G}_{2} / \mathrm{M}$ and $\mathrm{S}$ phases $(6,7)$. Previous studies have identified the expression levels of WEE1 in a variety of human tumor tissues (8-12). Decreased expression of WEE1 has been demonstrated in non-small cell lung cancer (NSCLC) and increased WEE1 expression has been identified in ovarian cancer, melanoma, osteosarcoma, glioblastoma and breast cancer. Notably, WEE1 expression was significantly associated with poor overall survival time in the analysis of 109 patients with 
ovarian cancer with post-chemotherapy effusions (13), suggesting that WEE1 may be a novel therapeutic target for ovarian cancer.

The direct effect of WEE1 inhibition on ovarian cancer cell viability requires study. MK1775, the first selective molecular inhibitor of WEE1, has been identified as an agent that primarily targets the $\mathrm{G}_{2} / \mathrm{M}$ checkpoint and exhibits a toxic effect (14). Subsequent studies were initiated to determine the synergistic antitumor role of MK1775 in combination therapies with conventional DNA damaging agents for ovarian, breast, prostate, pancreatic and colon cancer (15-18). An antitumor effect was observed to be dependent on the cytotoxicity exhibited by other combined DNA-damaging agents or a tumor protein 53 (p53)-defect in tumor cells $(14,16,17,19)$. The single-agent effect of MK1775 on tumor viability in vivo was initially identified in NSCLC (20), medulloblastoma (21) and sarcoma (22). In addition, previous studies have indicated that the cytotoxic effect of MK1775 was independent of p53 status $(10,22)$. However, in ovarian cancer, no significant antitumor effect was observed when nude mice bearing OVCAR-5 were treated with MK-1775 alone (23). The present study analyzed the cytotoxic effect of MK1775 as a single chemotherapy agent on ID8 and SKOV3 ovarian cancer cell lines in vitro. Furthermore, the antitumor activity of MK1775 in vivo was determined in ID8-bearing immunocompetent mice.

\section{Materials and methods}

Animals and reagents. C57BL/6 WT mice were purchased from Jackson Laboratory (Ben Harbour, ME, USA), while Dr Hans Schreiber (University of Chicago, Chicago, IL, USA) provided EG7 and B16F10 cell lines. LLC1, SKOV3 and OVCAR3 cell lines were purchased from the American Type Culture Collection (ATCC; Manassas, VA, USA). Mouse ID8 and ID8-OVA cells were obtained as previously described (24). The BPS-1 mouse melanoma cell was generated by this study group (25) from a spontaneously arising tumor in B-Raf proto-oncogene, serine/threonine kinase $\left[\mathrm{BRAF}^{(\mathrm{V} 600 \mathrm{E})}\right] /$ phosphatase and tensin homolog (PTEN) (Tyr::CreER; tyrosinase promoter/enhancer regions upstream of a tamoxifen/4-hydroxytamoxifen-inducible Cre recombinase fused to a mutated estrogen receptor ligand binding domain; Braf ${ }^{\mathrm{CA} /+}$; Pten ${ }^{\text {lox } 5 / \text { lox } 5}$, transgene for the Braf allele and the floxed Pten allele) transgenic mice (26,27). The animal studies were performed under the approval of the Institutional Animal Use Committees of the Northwestern University (Chicago, IL, USA). B16F10, ID8, ID8-OVA and BPS1 cells were maintained in RPMI 1640 medium (SigmaAldrich; Merck KGaA, Darmstadt, Germany), supplemented with $1 \%$ penicillin-streptomycin, $1 \%$ glutamine and $5 \%$ fetal bovine serum (FBS). SKOV3 and LLC1 cells were cultured in complete medium composed of Dulbecco's modified Eagle's medium (Sigma-Aldrich; Merck KGaA) supplemented with $10 \%$ FBS. All the antibodies for flow cytometry were obtained from BioLegend, Inc. (San Diego, CA, USA) or eBiosience (Thermo Fisher Scientific, Inc., Waltham, MA, USA). The annexin $\mathrm{V}$ apoptosis detection kit was purchased from Biolegend, Inc., and MTT kits were purchased from Roche Diagnostics (Basel, Switzerland).
In vitro cytotoxicity assays. An MTT assay was performed to determine the in vitro cytotoxicity of MK1775 in distinct mouse tumor cell lines, including B16F10, LLC1, BPS1, ID8 and EG7, and the human ovarian cancer SKOV3 cell line. Cell density was optimized to ensure that the cell viability for the duration of the treatment was within the linear range. According to the manufacturer's protocol, a variety of tumor cells in the logarithmic growth phase were plated (1,000 cells/well) in 96-well flat bottom plates and allowed to adhere prior to treatment. Subsequently, cells were treated in triplicates with vehicle dimethyl sulfoxide (DMSO) only, and a variety of concentrations of MK1775 dissolved in DMSO. On the basis of previous studies $(14,28)$, the following concentrations of MK1775 were used: $0.01,0.1,1.0$ and $10 \mu \mathrm{M}$, and negative control cells were treated with DMSO. At $72 \mathrm{~h}$ post-drug treatment, MTT was added to a final concentration of $1 \mathrm{mM}$ and the cells were incubated at $37^{\circ} \mathrm{C}$ in an atmosphere containing $5 \% \mathrm{CO}_{2}$. A total of $200 \mu 1$ solubilization solution was subsequently added to each well and plates were allowed to stand overnight at $37^{\circ} \mathrm{C}$. The absorbance was determined at $560 \mathrm{~nm}$ using a microplate reader. The half-maximal inhibitory concentration $\left(\mathrm{IC}_{50}\right)$ of MK1775 for ID8 and SKOV3 cells was calculated.

Flow cytometry analysis of apoptosis. ID8 and SKOV3 cells were plated in a $75-\mathrm{cm}^{2}$ dish $\left(1.5 \times 10^{4}\right.$ cells $\left./ \mathrm{ml}\right)$ and allowed to adhere overnight at $37^{\circ} \mathrm{C}$ prior to treatment. Following treatment with the specified concentrations of MK1775, the cell apoptosis assay was conducted using cell staining with annexin $\mathrm{V}(2.5 \mu \mathrm{g} / \mathrm{ml})$ and 7-aminoactinomycin D (7-AAD) $(1 \mu \mathrm{g} / \mathrm{ml})$ for $15 \mathrm{~min}$ at room temperature $\left(25^{\circ} \mathrm{C}\right)$ in the dark, according to the manufacturer's protocol. The apoptosis assay was performed 24 or $48 \mathrm{~h}$ after drug treatment using MACS Quant Analyzer (Miltenyi Biotec, Cologne, Germany). The data were analyzed using Flow Jo software version 10.0.7r2 (Tree Star, Inc., Ashland, OR, USA). Cells that stained negative for annexin V-allophycocyanin and 7-AAD were classified as not undergoing determinable apoptosis, double-positive cells were classified as late-state apoptosis, single-positive cells for annexin- $\mathrm{V}$ were classified as early apoptosis and singlepositive cells for 7-AAD were classified as dead or necrotic cells.

Analysis of the cell cycle. The treatment conditions were the same as in the apoptosis assay. The treated tumor cells $\left(1 \times 10^{6}\right.$ cells) were detached and fixed in ice-cold $75 \%$ ethanol for $4 \mathrm{~h}$ on ice. Cells were subsequently washed with PBS and stained with $5 \mu \mathrm{g} / \mathrm{ml}$ propidium iodide (PI; cat number: 421301, Biolegend, Inc.) and $50 \mu \mathrm{g} / \mathrm{ml}$ RNase for $30 \mathrm{~min}$ at $4^{\circ} \mathrm{C}$. The cell cycle of ID8 cells was determined using PI staining, whereas that of SKOV3 cells was determined by DAPI (cat number: 422801, Biolegend, Inc.) staining $\left(1 \mu \mathrm{g} / \mathrm{ml}\right.$ at $4^{\circ} \mathrm{C}$ for $30 \mathrm{~min}$ ). The flow cytometry analysis was performed using MACS Quant Analyzer (Miltenyi Biotec) and the proportions of cells in $\mathrm{G}_{1}, S$, and $\mathrm{G}_{2} / \mathrm{M}$ phases were analyzed using Flow Jo Cell Cycle software version 10.0.7r2 (Tree Star, Inc., Ashland, OR, USA).

Western blot analysis. ID8 cells were treated with DMSO, $0.5 \mu \mathrm{M}$ MK1775 or $1 \mu \mathrm{M}$ MK1775 for $48 \mathrm{~h}$, followed by a wash with PBS. Cells were subsequently lysed using 
radioimmunoprecipitation assay buffer, including phenylmethylsulfonyl fluoride and a protease inhibitor cocktail (Roche Diagnostics, Indianapolis, IN, USA). Protein concentration was determined using BCA protein assay kit according to manufacturer's protocol (Thermo Fisher Scientific, Inc., Waltham, MA, USA). The proteins were separated on SDS-PAGE (12\% gel) and subsequently transferred onto polyvinylidene fluoride membranes. Membranes were blocked in 5\% skimmed milk for $2 \mathrm{~h}$ at room temperature and incubated with a primary antibody against phosphorylated-CDC2 (residue Typ ${ }^{15}$ ), a target of WEE1 kinase (1:1,000; catalog no. 4539; Cell Signaling Technology, Inc., Danvers, MA, USA), at $4^{\circ} \mathrm{C}$ overnight. Membranes were washed with Tris-buffered saline-Tween-20 (TBST) 3 times prior to incubation at room temperature for $2 \mathrm{~h}$ with the appropriate secondary antibody conjugated to horseradish peroxidase $(1: 2,000$; catalog no. 7074; Cell Signaling Technology, Inc.). Subsequently, membranes were washed 3 times with TBST and developed using enhanced chemiluminescence (Thermo Fisher Scientific, Inc.). Blots were visualized using C-DiGit Blot Scanner (LI-COR Biosciences, Lincoln, NE, USA). $\beta$-actin served as a loading control.

Tumor challenges. Mice were housed in single-sex groups, and had ad libitum access to bottled acidified water $(\mathrm{pH} 2.8$ to 3.1) and feed pellets with $6 \%$ fat (NIH 31M, Purina Mills, Richmond, IN, USA). The number of room air changes/hour was maintained at $15 \pm 1$, temperature at $22 \pm 2^{\circ} \mathrm{C}$, and relative humidity at $45 \pm 5 \%$, with a $14: 10$ h light: dark cycle. ID8-OVA tumor cells $\left(6 \times 10^{6}\right)$ in suspension were challenged intraperitoneally into 6-8 week-old C57BL/6 WT female mice (20-25 g body weight) $(n=8)$ and tumor progression was monitored every 7 days by determining the abdominal circumferences of the mice with the aid of a wire measured by a ruler, expressed in millimeters. At day 30 after challenge, when abdominal swelling was determinable, mice were randomly divided into two groups ( $\mathrm{n}=4$ in each). DMSO or MK1775 treatment was administered daily at $50 \mathrm{mg} / \mathrm{kg}$. The ascites fluid from ID8-bearing mice was harvested with a 20-gauge needle for volume measurement 30 days after MK1775 treatment. The endpoint criterion was a gain of $>20 \%$ of body weight compared to the pre-study weight. Mice were euthanized by combined high dose of $\mathrm{CO}_{2}$ gas (a flow rate of 1-3 1 per minute for a 101 volume chamber) followed by cervical dislocation.

Statistical analysis. Statistical analysis was performed using SPSS software (version 10.0; SPSS Inc., Chicago, IL, USA). Statistical significance between two groups was assessed using an unpaired Student's two-tailed t-test and multiple comparisons between the groups were determined using an analysis of variance (Student-Newman-Keuls). $\mathrm{P}<0.05$ was considered to indicate a statistically significant difference.

\section{Results}

Cytotoxic effect of MK1775 on a variety of tumor cell lines. The in vitro cytotoxic effect of MK1775 on distinct tumor cells was assessed using an MTT assay. As presented in Fig. 1, MK1775 treatment decreased the viability of murine melanoma B16F10 and BPS1, lymphoma EG7, ovarian cancer ID8, LLC1 lung cancer and human ovarian cancer SKOV3 cells in a dose-dependent manner. The responses of the tumor cells to MK1775 at a variety of concentrations were indicative of the relative cytotoxicity of MK1775 against distinct tumor cell lines. Notably, the mean $\mathrm{IC}_{50}$ of MK1775 to ID8 and SKOV3 cells were 0.75 and $0.46 \mu \mathrm{M}$, respectively. The results of the present study demonstrated that ID8 and SKOV3 ovarian cancer cells were sensitive to MK1775 treatment.

MK1775 as a single agent induces the apoptosis of ID8 and SKOV3 ovarian cancer cells. A cell apoptosis assay was conducted in ovarian cancer ID8 and SKOV3 cell lines to examine the cytotoxic activity of MK1775. Flow cytometry was used to determine annexin V/7-AAD expression and the stages of apoptosis. Previously, studies have identified that ID8 cells express WT p53 (29), whereas SKOV3 cells have null p53 (30). Fig. 2 presents the proportion of cells undergoing early, late and end-stage apoptosis. In ID8 and SKOV3 cells, MK1775 induced tumor cell apoptosis. SKOV3 cells were more susceptible to MK1775-induced apoptosis compared with ID8 cells. The results of the present study identified the cytotoxic role of MK1775 as a single chemotherapy agent against either WT p53 or p53-defective cell lines. Furthermore, a p53 defect may sensitize tumor cells to MK1775 treatment.

MK1775 treatment abrogates the $G_{2} / M$ checkpoint of ID8 cells through attenuating the phosphorylation of CDK1. To determine the underlying molecular mechanism of cell death induced by MK1775 treatment, independent of p53, cell cycle analysis and a western blot analysis was performed on ID8 cell lines with WT p53. As presented in Fig. 3, MK1775 treatment arrested tumor cells in $S$ phase and abrogated the $\mathrm{G}_{2} / \mathrm{M}$ cell cycle checkpoint. The abrogation of the $\mathrm{G}_{2}$ DNA damage checkpoint resulted in cell death and the presence of a sub- $\mathrm{G}_{1}$ peak indicated that MK1775 treatment induced cell apoptosis, which was consistent with the results from the cell apoptosis assay (Fig. 2). In addition, a dose-dependent decrease in phosphorylated-CDC2 $\left(\right.$ Tyr $\left.^{15}\right)$ was observed in ID8 cells following MK1775 treatment (Fig. 3C), indicating that MK1775 may abrogate the $\mathrm{G}_{2}$ checkpoint through the phosphorylation of CDC2. A significant increase in cleaved poly (ADP-ribose) polymerase and caspase-3, two markers of apoptosis, has been associated with decreased levels of phosphorylated-CDC2 $\left(\mathrm{Tyr}^{15}\right.$ ) and was a result of MK1775 treatment (31). Deregulation of CDC2 activity may trigger the activation of caspase-3 and apoptosis (32). These results together demonstrate a proof-of-mechanism for this novel inhibitor of WEE1, with evidence of decreased phosphorylated-CDC2 $\left(\mathrm{Tyr}^{15}\right)$ levels in ovarian cancer cells. Furthermore, the cell cycle (Fig. 3B) and phosphorylated-CDC2 (Fig. 3D) in SKOV3 cells with p53 mutations were analyzed in the present study. Notably, the observed effect of MK1775 treatment on the cell cycle was increased in SKOV3 cells compared with that observed in ID8 cells, which was consistent with the results of the MTT and apoptosis assays, suggesting that a p53 defect may sensitize tumor cells to MK1775 treatment.

Antitumor effect of MK1775 in syngeneic mouse model of ovarian cancer. To determine the in vivo antitumor activity of MK1775, a syngeneic ID8 ovarian cancer model was used. C57BL/6 mice were challenged with ID8 cells and treated 
A
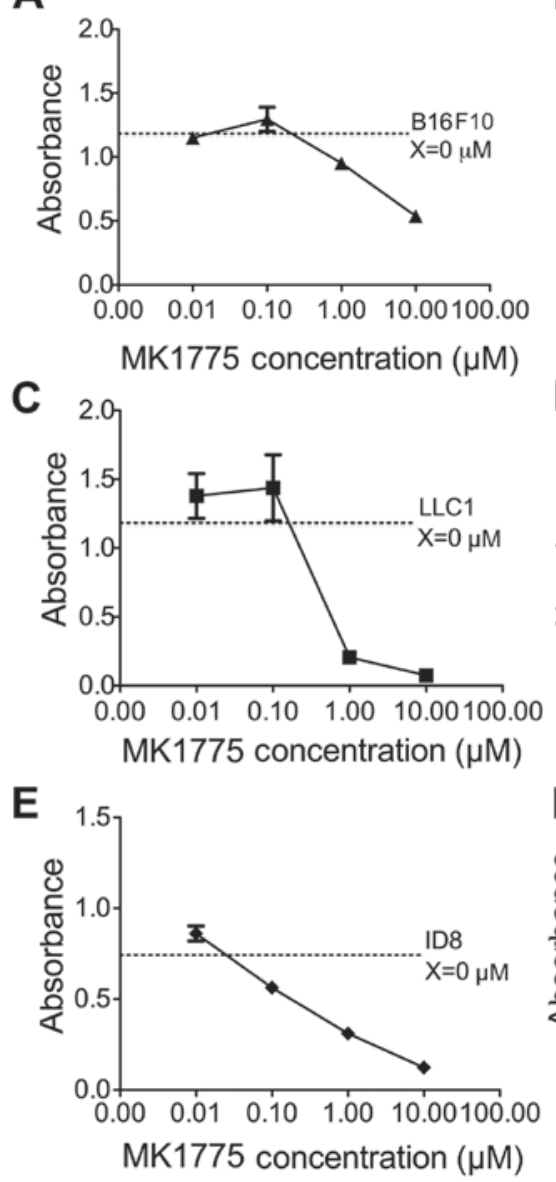

B
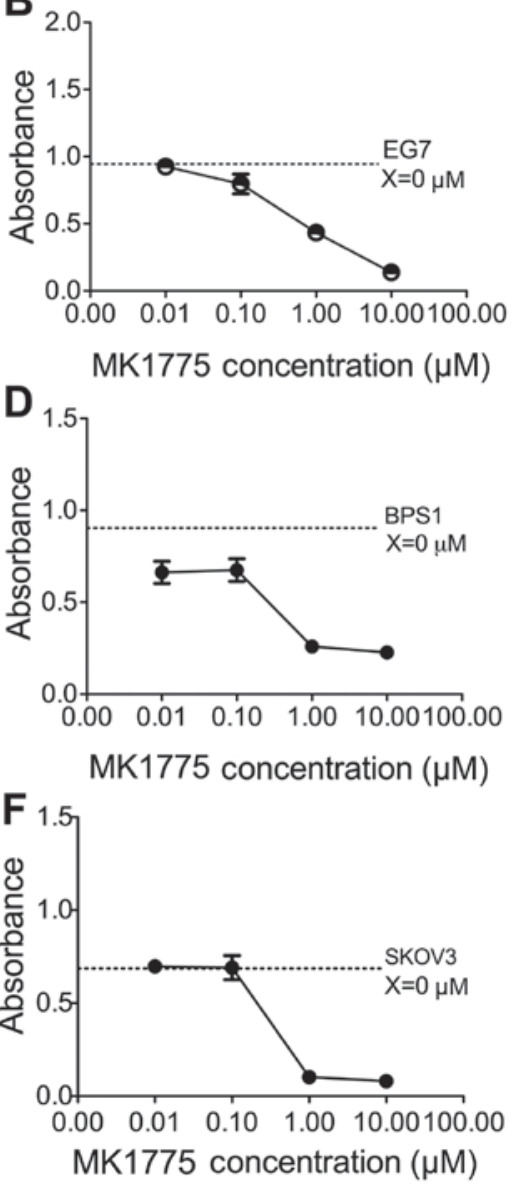

Figure 1. MK1775 as a single agent inhibits the viability of cells in a variety of tumors. (A) B16F10, (B) EG7, (C) LLC1, (D) BPS1, (E) ID8 and (F) SKOV3 cells were treated with a variety of concentrations of MK1775, as indicated, for 3 days. Cell viability was analyzed using an MTT assay.

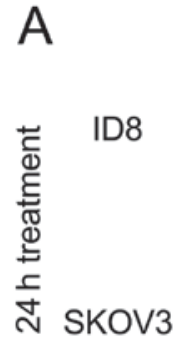

DMSO

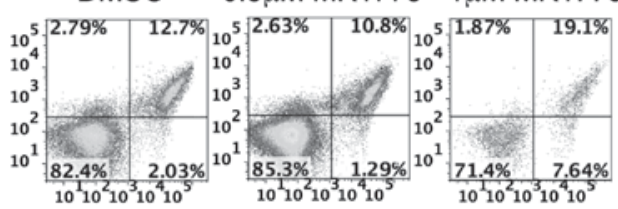

SKOV3
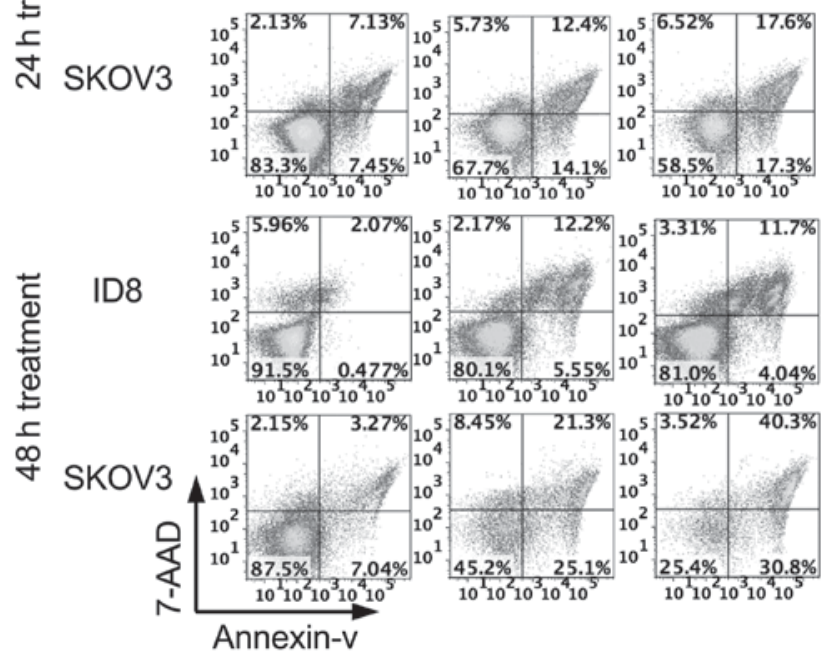

$\mathrm{B}$
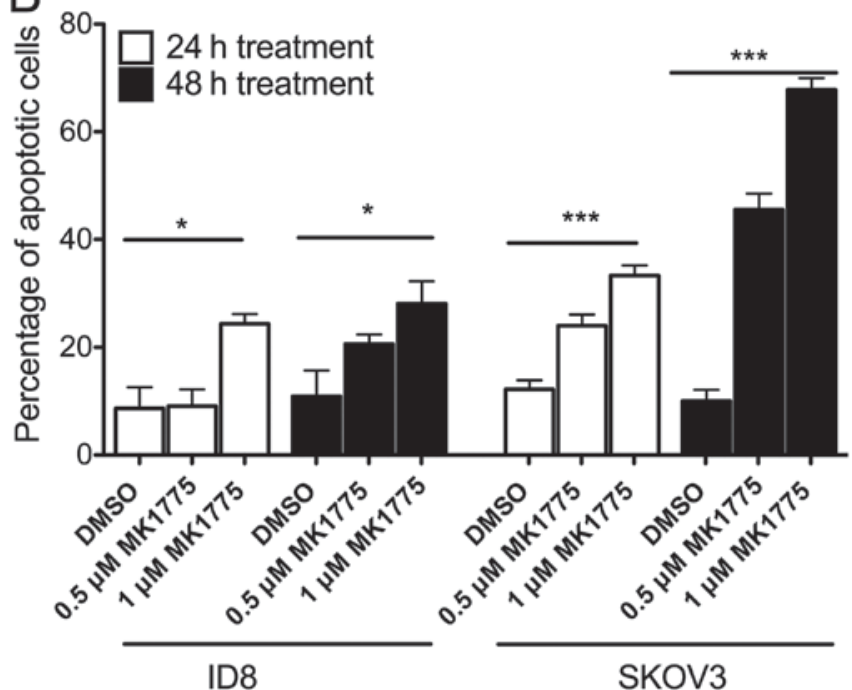

Figure 2. MK1775 alone induces the apoptosis of ovarian cancer cells. Cell apoptosis was determined using annexin v/7-AAD staining of ID8 and SKOV3 cells, 24 or $48 \mathrm{~h}$ after treatment with DMSO (controls), or 0.5 or $1 \mu \mathrm{M}$ MK1775. (A) Representative flow plots of ID8 and SKOV3 cells following treatment with DMSO or MK1775. (B) Histogram indicating the proportion of apoptotic tumor cells (annexin ${ }^{+}$) in ID8 and SKOV3 cells following treatment with DMSO or MK1775. Error bars represent the standard error of the mean. ${ }^{*} \mathrm{P}<0.05,{ }^{* *} \mathrm{P}<0.01,{ }^{* * *} \mathrm{P}<0.0001 .7-\mathrm{AAD}, 7$-aminoactinomycin $\mathrm{D}$; DMSO, dimethyl sulfoxide. 
A

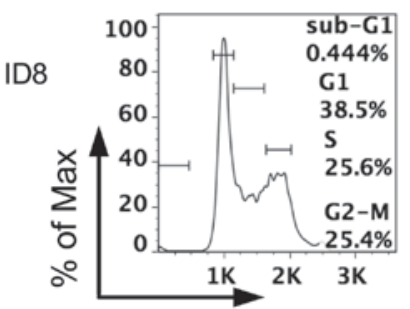

PI

B

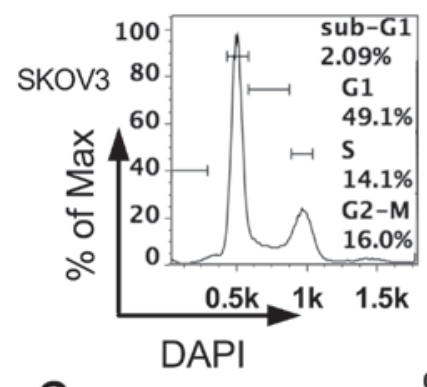

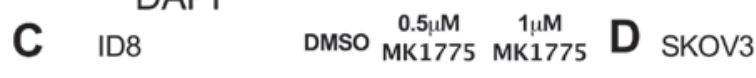

$0.5 \mu \mathrm{M}$ МК 1775

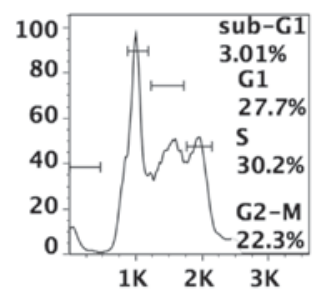

$0.5 \mu \mathrm{M}$ MK1775

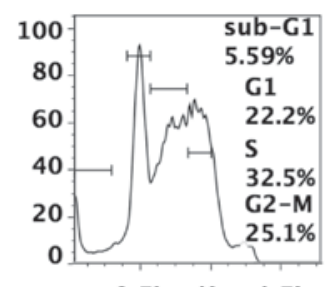

$0.5 \mathrm{k} \quad 1 \mathrm{k} \quad 1.5 \mathrm{k}$
$1 \mu \mathrm{M}$ MK1775

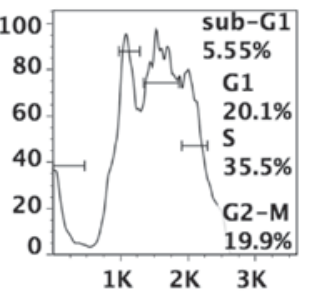

$1 \mu \mathrm{M} \mathrm{MK} 1775$
p-CDC2 $2^{\text {Tyr15 }}$

$\beta$-actin

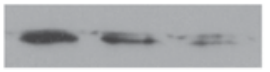

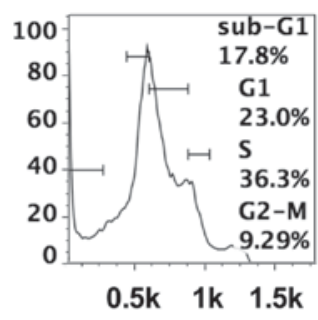

p-CDC2 $2^{\text {Tyr15 }}$

$\beta$-actin

Figure 3. MK1775 treatment abrogates the $\mathrm{G}_{2} / \mathrm{M}$ checkpoint of ID8 cells, through decreasing the phosphorylation of cyclin-dependent kinase 1 . $\beta$-actin was used as a loading control. (A) Cell cycle analysis, performed using flow cytometry $48 \mathrm{~h}$ after treatment with DMSO, or $0.5 \mu \mathrm{M}$ or $1 \mu \mathrm{M}$ MK1775. (B) Cell cycle analysis, performed using flow cytometry $48 \mathrm{~h}$ after treatment with DMSO, or $0.5 \mu \mathrm{M}$ or $1 \mu \mathrm{M}$ MK1775. (C) Phosphorylated CDC2 (Tyr ${ }^{15}$ ) protein levels, determined using western blot $48 \mathrm{~h}$ after treatment with $0.5 \mu \mathrm{M}$ or $1 \mu \mathrm{M}$ MK1775. (D) Phosphorylated CDC2 (Tyr ${ }^{15}$ ) protein levels determined using western blotting, $48 \mathrm{~h}$ after treatment with $0.5 \mu \mathrm{M}$ or $1 \mu \mathrm{M}$ MK1775. DMSO, dimethyl sulfoxide; PI, propidium iodide; p-CDC2, phosphorylated cyclin-dependent kinase 1 .
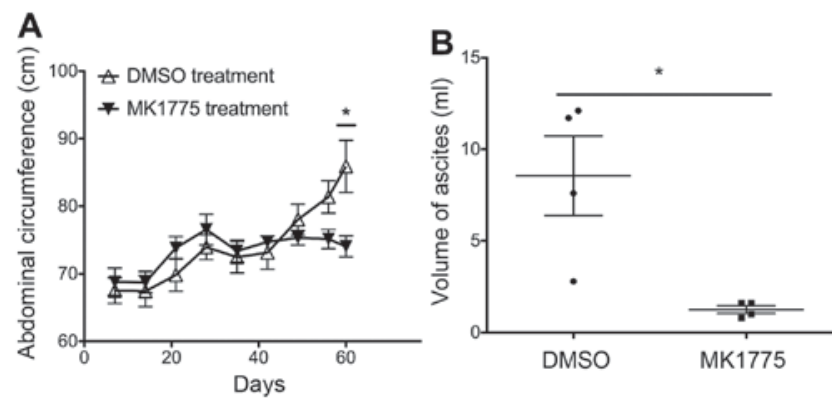

Figure 4. MK1775 as a single agent inhibits ID8 ovarian tumor viability in vivo. C57BL/6 WT mice $(\mathrm{n}=8)$ were injected intraperitoneally with ID8 cells. Mice were treated with MK1775 daily at $50 \mathrm{mg} / \mathrm{kg}$, starting from day 30 when the tumors were established. (A) Tumor progression was monitored weekly by determining the abdominal circumferences. (B) Volume of ascites from ID8-bearing mice was determined 30 days after MK1775 treatment. ${ }^{*} \mathrm{P}<0.05$. DMSO, dimethyl sulfoxide.

daily with MK1775 or DMSO at day 30 post-challenge. The dose of MK1775 was converted and defined as $50 \mathrm{mg} / \mathrm{kg}$, on the basis of the data from an initial phase I clinical trial (33). A significant inhibition of ovarian tumor progression was identified from 2 weeks after MK1775 treatment, as indicated by the abdominal circumferences (Fig. 4A). In addition, MK1775 treatment alone significantly decreased the production of malignant ascites from ID8-bearing mice at the advanced stage (Fig. 4B).

\section{Discussion}

Due to the poor prognosis of ovarian cancer patients, novel therapies are required. DNA damage checkpoints are critical for maintaining the integrity of the cell genome. As a key regulator of the $\mathrm{G}_{2} / \mathrm{M}$ transition in the cell cycle, WEE1 has been considered as a promising target for cancer therapy. Notably, MK1775 as a selective and potent inhibitor of WEE1, is currently under clinical evaluation as a single-agent treatment and potentiates the DNA damage caused by cytotoxic chemotherapies or radiation therapy. In the present study, the in vitro and in vivo antitumor effect of MK1775 was evaluated as a single-agent in ovarian cancer.

Previous studies have identified the function of MK1775 in enhancing the sensitivity of tumor cells to the traditional DNA-damaging agents or radiotherapy (11,14-17). In addition, the synergistic antitumor activity of MK1775 was observed in combination therapies for ovarian, breast, prostate, pancreatic and colon cancer, and the effect was identified to be dependent on the cytotoxicity of other DNA-damaging agents or a 
p53-defect in tumor cells (14-16). For ovarian cancer, a phase II clinical trial is underway to evaluate the antitumor effects exhibited by the combination of MK1775, paclitaxel and carboplatin, compared with that exhibited by combined paclitaxel and carboplatin (18). Furthermore, a previous clinical trial demonstrated the therapeutic benefit from combining MK1775 with carboplatin in patients with epithelial ovarian cancer who are platinum-resistant and exhibit mutated p53 (34). Mutations or lack of functional p53 often cause a defective $\mathrm{G}_{1} / \mathrm{S}$ checkpoint in cancer cells. Therefore, the effectiveness of DNA damaging treatment may be augmented by abrogation of the G2/M checkpoint in these cancer cells while sparing normal cells with an intact G/S checkpoint (35-37). Studies have focused on the dual inhibition of components of the ataxia telangiectasia-related-checkpoint kinase 1 (Chk1)WEE1 axis, which exhibits a synergistic cytotoxic effect and simultaneously inhibits Chk1 and WEE1 through disrupting the cell cycle checkpoint regulation $(23,38,39)$.

Previous studies have identified the potential use of MK1775 as a single antitumor agent (20-22); however, whether the mono-therapeutic activity of MK1775 is dependent on mutant p53 remains unknown. The results of the present study demonstrated that MK1775 serves as a single agent to induce cell apoptosis in distinct cancer cell lines, independent of p53 status. In addition, a p53 defect may sensitize ovarian cancer cells to MK1775 treatment. Although no significant inhibition of tumor viability was determined in MK1775-treated nude mice bearing OVCAR-5, which is null p53 (25), additional studies are required to determine the association between tumor p53 deficient status and the efficacy of MK1775 treatment.

The antitumor effect of MK1775 as a single-agent has been evaluated in C57BL/6 mice harboring syngeneic ID8 ovarian tumors with WT BRCA1 $(40,41)$. A significant decrease in the accumulation of malignant ascites was observed following MK1775 treatment, suggesting that MK1775 treatment alone has a potent antitumor effect and is tolerable for preclinical ovarian cancer therapy. These results identified that targeting WEE1 by MK1775 monotherapy is not limited to p53-mutant or BRCA1 mutant cancers. In addition to DNA damage and the cell cycle, other specific underlying cellular mechanisms may be implicated when WEE1 is inhibited, providing insights into the development of novel combination therapy with WEE1 inhibitors. To the best of our knowledge, the present study was the first to demonstrate the efficacy of WEE1 inhibition by MK1775 in ovarian cancer in immunocompetent mice. As host components, including immune cells, may express WEE1, the effects of MK1775 on host cells and cancer cells requires study. The results of the present study indicate that MK1775, as a single-agent therapy, results in WEE1 inhibition and the subsequent activation of CDC2, thereby suppressing ovarian tumor viability. The results of the present study suggest potential clinical applications for MK1775, which may be a therapeutic benefit for patients with ovarian cancer, independent of p53 status.

\section{Acknowledgements}

The present study was supported by the National Natural Science Foundation of China (grant no. 81171985), the National Institute of Health (grant no. CA149669), Northwestern
Memorial Foundation-Friends of Prentice Grants Initiative, SPORE Pilot Award (grant no. P50 CA090386) and Northwestern University RHLCCC Flow Cytometry Facility, a Cancer Center Support Grant (NCI CA060553).

\section{References}

1. Siegel R, Naishadham D and Jemal A: Cancer statistics, 2013. CA Cancer J Clin 63: 11-30, 2013.

2. Ferlay J, Shin HR, Bray F, Forman D, Mathers C and Parkin DM: Estimates of worldwide burden of cancer in 2008: GLOBOCAN 2008. Int J Cancer 127: 2893-2917, 2010.

3. Parker LL and Piwnica-Worms H: Inactivation of the p34cdc2cyclin B complex by the human WEE1 tyrosine kinase. Science 257: 1955-1957, 1992.

4. Watanabe N, Broome M and Hunter T: Regulation of the human WEE1Hu CDK tyrosine 15-kinase during the cell cycle. EMBO J 14: 1878-1891, 1995.

5. McGowan $\mathrm{CH}$ and Russell P: Cell cycle regulation of human WEE1. EMBO J 14: 2166-2175, 1995.

6. Nigg EA: Cyclin-dependent protein kinases: Key regulators of the eukaryotic cell cycle. Bioessays 17: 471-480, 1995.

7. Edgar BA and Lehner CF: Developmental control of cell cycle regulators: A fly's perspective. Science 274: 1646-1652, 1996.

8. Magnussen GI, Holm R, Emilsen E, Rosnes AK, Slipicevic A and Flørenes VA: High expression of Weel is associated with poor disease-free survival in malignant melanoma: Potential for targeted therapy. PLoS One 7: e38254, 2012.

9. Magnussen GI, Hellesylt E, Nesland JM, Trope CG, Flørenes VA and Holm R: High expression of wee1 is associated with malignancy in vulvar squamous cell carcinoma patients. BMC Cancer 13: 288, 2013.

10. Mir SE, De Witt Hamer PC, Krawczyk PM, Balaj L, Claes A, Niers JM, Van Tilborg AA, Zwinderman AH, Geerts D, Kaspers GJ, et al: In silico analysis of kinase expression identifies WEE1 as a gatekeeper against mitotic catastrophe in glioblastoma. Cancer Cell 18: 244-257, 2010.

11. PosthumaDeBoer J, Wördinger T, Graat HC, van Beusechem VW, Helder MN, van Royen BJ and Kaspers GJ: WEE1 inhibition sensitizes osteosarcoma to radiotherapy. BMC Cancer 11: 156, 2011.

12. Iorns E, Lord CJ, Grigoriadis A, McDonald S, Fenwick K, Mackay A, Mein CA, Natrajan R, Savage K, Tamber N, et al: Integrated functional, gene expression and genomic analysis for the identification of cancer targets. PLoS One 4: e5120, 2009.

13. Slipicevic A, Holth A, Hellesylt E, Tropé CG, Davidson B and Flørenes VA: Weel is a novel independent prognostic marker of poor survival in post-chemotherapy ovarian carcinoma effusions. Gynecol Oncol 135: 118-124, 2014.

14. Hirai H, Iwasawa Y, Okada M, Arai T, Nishibata T, Kobayashi M, Kimura T, Kaneko N, Ohtani J, Yamanaka K, et al: Small-molecule inhibition of Weel kinase by MK-1775 selectively sensitizes p53-deficient tumor cells to DNA-damaging agents. Mol Cancer Ther 8: 2992-3000, 2009.

15. Bridges KA, Hirai H, Buser CA, Brooks C, Liu H, Buchholz TA, Molkentine JM, Mason KA and Meyn RE: MK-1775, a novel Weel kinase inhibitor, radiosensitizes p53-defective human tumor cells. Clin Cancer Res 17: 5638-5648, 2011.

16. Rajeshkumar NV, De Oliveira E, Ottenhof N, Watters J, Brooks D, Demuth T, Shumway SD, Mizuarai S, Hirai H, Maitra A and Hidalgo M: MK-1775, a potent Wee1 inhibitor, synergizes with gemcitabine to achieve tumor regressions, selectively in p53-deficient pancreatic cancer xenografts. Clin Cancer Res 17: 2799-2806, 2011.

17. Hirai H, Arai T, Okada M, Nishibata T, Kobayashi M, Sakai N, Imagaki K, Ohtani J, Sakai T, Yoshizumi T, et al: MK-1775, a small molecule Weel inhibitor, enhances anti-tumor efficacy of various DNA-damaging agents, including 5-fluorouracil. Cancer Biol Ther 9: 514-522, 2010.

18. http://clinicaltrials.gov/show/NCT01357161 [accessed 23.11.13].

19. Mueller S, Hashizume R, Yang X, Kolkowitz I, Olow AK, Phillips J, Smirnov I, Tom MW, Prados MD, James CD, et al: Targeting Wee1 for the treatment of pediatric high-grade gliomas. Neuro Oncol 16: 352-360, 2014.

20. Guertin AD, Li J, Liu Y, Hurd MS, Schuller AG, Long B, Hirsch HA, Feldman I, Benita Y, Toniatti C, et al: Preclinical evaluation of the WEE1 inhibitor MK-1775 as single-agent anticancer therapy. Mol Cancer Ther 12: 1442-1452, 2013. 
21. Harris PS, Venkataraman S, Alimova I, Birks DK, Balakrishnan I, Cristiano B, Donson AM, Dubuc AM, Taylor MD, Foreman NK, et al: Integrated genomic analysis identifies the mitotic checkpoint kinase WEE1 as a novel therapeutic target in medulloblastoma. Mol Cancer 13: 72, 2014.

22. Kreahling JM, Gemmer JY, Reed D, Letson D, Bui M and Altiok S: MK1775, a selective Weel inhibitor, shows single-agent antitumor activity against sarcoma cells. Mol Cancer Ther 11: 174-182, 2012.

23. Carrassa L, Chilà R, Lupi M, Ricci F, Celenza C, Mazzoletti M, Broggini $\mathrm{M}$ and Damia G: Combined inhibition of Chk1 and Wee1: In vitro synergistic effect translates to tumor growth inhibition in vivo. Cell Cycle 11: 2507-2517, 2012.

24. Jin D, Fan J, Wang L, Thompson LF, Liu A, Daniel BJ, Shin T, Curiel TJ and Zhang B: CD73 on tumor cells impairs antitumor T-cell responses: A novel mechanism of tumor-induced immune suppression. Cancer Res 70: 2245-2255, 2010.

25. Dominguez D, Ye C, Geng Z, Chen S, Fan J, Qin L, Long A, Wang L, Zhang Z, Zhang Y, et al: Exogenous IL-33 restores dendritic cell activation and maturation in established cancer. J Immunol 198: 1365-1375, 2017.

26. Dankort D, Curley DP, Cartlidge RA, Nelson B, Karnezis AN, Damsky WE Jr, You MJ, DePinho RA, McMahon M and Bosenberg M: Braf(V600E) cooperates with Pten loss to induce metastatic melanoma. Nat Genet 41: 544-552, 2009.

27. Hooijkaas AI, Gadiot J, van der Valk M, Mooi WJ and Blank CU: Targeting BRAFV600E in an inducible murine model of melanoma. Am J Pathol 181: 785-794, 2012.

28. Van Linden AA, Baturin D, Ford JB, Fosmire SP, Gardner L, Korch C, Reigan P and Porter CC: Inhibition of Weel sensitizes cancer cells to antimetabolite chemotherapeutics in vitro and in vivo, independent of p53 functionality. Mol Cancer Ther 12 : 2675-2684, 2013.

29. Lim ST, Miller NL, Nam JO, Chen XL, Lim Y and Schlaepfer DD: Pyk2 inhibition of $\mathrm{p} 53$ as an adaptive and intrinsic mechanism facilitating cell proliferation and survival. J Biol Chem 285: 1743-1753, 2010 .

30. Anglesio MS, Wiegand KC, Melnyk N, Chow C, Salamanca C, Prentice LM, Senz J, Yang W, Spillman MA, Cochrane DR, et al Type-specific cell line models for type-specific ovarian cancer research. PLoS One 8: e72162, 2013.
31. Do K, Doroshow JH and Kummar S: Wee1 kinase as a target for cancer therapy. Cell Cycle 12: 3159-3164, 2013.

32. Gu L, Zheng H, Murray SA, Ying H and Jim Xiao ZX: Deregulation of Cdc2 kinase induces caspase-3 activation and apoptosis. Biochem Biophys Res Commun 302: 384-391, 2003.

33. Targeting p53 mutant ovarian cancer: Phase I result of the WEE1 inhibitor MK-1775 with carboplatin plus paclitaxel in patients (pts) with platinum-sensitive, p53-mutant ovarian cancer (OC). 45th Annual Meeting of the American Society of Clinical Oncology, Meeting Library (http://meeting library. asco.org), 2013.

34. http://clinicaltrials.gov/show/NCT01164995. Accessed November 23, 2013.

35. Bucher $\mathrm{N}$ and Britten CD: G2 checkpoint abrogation and checkpoint kinase-1 targeting in the treatment of cancer. $\mathrm{Br} J$ Cancer 98: 523-528, 2008.

36. Kawabe T: $\mathrm{G} 2$ checkpoint abrogators as anticancer drugs. Mol Cancer Ther 3: 513-519, 2004.

37. Vance S, Liu E, Zhao L, Parsels JD, Parsels LA, Brown JL, Maybaum J, Lawrence TS and Morgan MA: Selective radiosensitization of p53 mutant pancreatic cancer cells by combined inhibition of Chk1 and PARP1. Cell Cycle 10: 4321-4329, 2011.

38. Chilà R, Basana A, Lupi M, Guffanti F, Gaudio E, Rinaldi A, Cascione L, Restelli V, Tarantelli C, Bertoni F, et al: Combined inhibition of Chk1 and Wee1 as a new therapeutic strategy for mantle cell lymphoma. Oncotarget 6: 3394-3408, 2015.

39. Magnussen GI, Emilsen E, Giller Fleten K, Engesæter B, NähseKumpf V, Fjær R, Slipicevic A and Flørenes VA: Combined inhibition of the cell cycle related proteins Wee1 and Chk1/2 induces synergistic anti-cancer effect in melanoma. BMC Cancer 15: 462, 2015

40. Huang J, Wang L, Cong Z, Amoozgar Z, Kiner E, Xing D, Orsulic S, Matulonis U and Goldberg MS: The PARP1 inhibitor BMN 673 exhibits immunoregulatory effects in a Brca1(-/-) murine model of ovarian cancer. Biochem Biophys Res Commun 463: 551-556, 2015.

41. Quinn JE, Carser JE, James CR, Kennedy RD and Harkin DP: BRCA1 and implications for response to chemotherapy in ovarian cancer. Gynecol Oncol 113: 134-142, 2009. 